\title{
Implementing Viscous Plane Damper to Prevent Pounding Between Adjacent Reinforced Concrete Buildings
}

\author{
Asal Ameen Taha, Farzad Hejazi \\ ${ }^{1}$ Department of Civil Engineering, Faculty of Engineering, University Putra Malaysia \\ Serdang, Selangor Darul Ehsan, Malaysia. \\ asal1994asal@yahoo.com; farzad@upm.edu.my
}

\begin{abstract}
The pounding of adjacent building is one of the key issues that occurs during earthquakes, which has caused severe damage in buildings. This paper presents an analysis of using an innovative viscous plane damper in the gap between adjacent reinforced concrete (RC) buildings subjected to seismic loads. For this purpose, parallel RC structures of three and six storeys are considered, and a viscous plane damper is implemented in the gap between the two adjacent structures. The effect of the viscos plane damper on the pounding of the considered adjacent RC structure is studied. The finite element modelling and seismic time history analysis of the buildings were performed using Arcs 3D software to prepare the building model. The maximum displacements in horizontal, transverse, and vertical directions are evaluated. Two stages of analysis were conducted. The first stage analysed three-storey and six-storey buildings independently. The results of the first stage were validated with experimental and numerical results. The second stage was analysed by combining two buildings with different storey heights with and without the viscous plane damper. The results showed an effective reduction in displacement values at around $23.15 \%$ horizontally, $35.5 \%$ transversely, and $14.0 \%$ vertically. Therefore, the inno vative damper significantly decreased pounding between RC buildings.
\end{abstract}

Keywords: Damping; pounding; reinforced concrete building; seismic loads; viscous damper.

\section{Introduction}

During past earthquakes, buildings suffered damage due to pounding. Pounding is defined as a collision between two buildings or different parts of the same building, leading to severe damage or sometimes complete collapse [1]. This phenomenon was observed during the Niigata (M6.8, 2007) [2], Wenchuan (M7.9, 2008) [3], and L'Aquila (M6.3, 2009) earthquakes [4].

Many researchers have conducted studies to understand pounding. The case of several adjacent buildings subjected to pounding was examined. The displacement of exterior structures may be amplified, while interior structures may experience amplification or de-amplification, depending on the ratio of the natural periods [5]. Papadrakakis et al. (1996) developed a three-dimensional (3D) finite element model to simulate pounding between adjacent buildings. They observed that, during pounding, the response of stiff structures showed more structural integrity compared with flexible structures [6]. Leibovich et al. (1996) studied the effects of the impact eccentricity on two sets of symmetric and asymmetric models aligned with respect to each other for several gap widths and the effects of torsional eccentricity on lateral frequency ratios. The amplification of asymmetric buildings is higher than that of symmetric buildings [7].

In contrast, a 3D analysis of the pounding between adjacent structures was conducted where two single-storey reinforced concrete (RC) buildings are considered [1] . Buildings with different setbacks and unequal storey levels are analysed using SAP 2000 to study the torsional effects due to pounding. The results of this study show that the effect of collision is greater when structures are kept at extreme levels of setback [1](see Fig. 1).

Chau and Wei (2011) performed a shake table test to study pounding between two structures. The experimental results were compared with the results from an analytical model where the impact was modelled using the nonlinear Hertz contact law. They discovered that the stand-off attains maximum displacement when the excitation frequency is close to that of the more flexible building [8]. Gong and Hao (2005) [9] studied torsional pounding between an asymmetric and symmetric onestorey structures subjected to bi-directional ground motion. The results proved that increasing the torsional stiffness of the asymmetric adjacent structure reduced the torque of both structures. Reducing the eccentricity of the asymmetric structure substantially reduced torque but had little effect on shear forces of both structures or on the torque of the adjacent symmetric structure [9]. Hence, in this paper, an innovative viscous plane damper is used in the gap between adjacent multi-storey RC 
buildings under seismic loads to prevent the pounding effects and improve the isolation system between adjacent RC frame buildings.

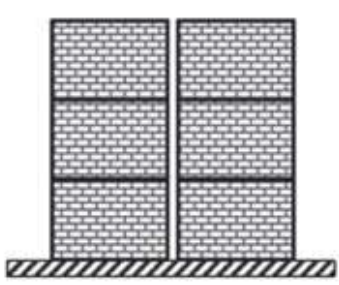

(a)

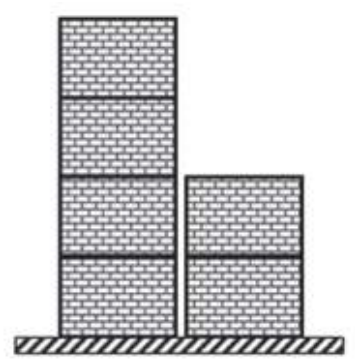

(b)

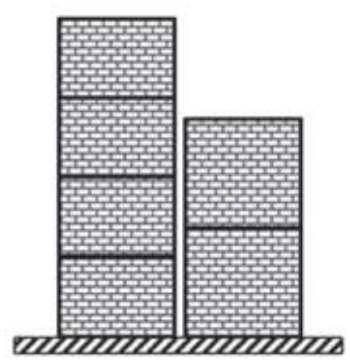

(c)

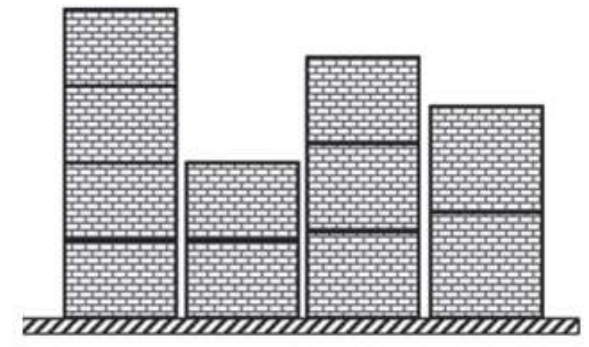

(d)

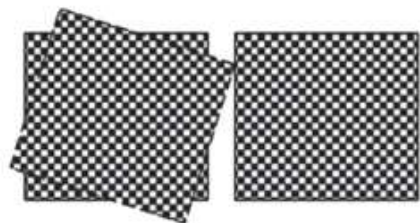

(e)

Fig. 1: Representation of different places where pounding occurs [1].

\section{Building Dimensions and Properties}

The typical dimensions of the panels of the RC model buildings were $1.8 \mathrm{~m}$ in the horizontal (X) direction and 2.4 $\mathrm{m}$ in the transverse direction $(\mathrm{Z})$. The typical height of each storey was $2 \mathrm{~m}$ in the vertical direction (Y). The structural modelling of buildings was conducted in two stages and included four models of RC buildings. The four models followed the dimensions and mechanical properties of the experimental study by Lu et al. (2008) [10] and the numerical study by Farzad et al. (2015) [11] (see Figs. 2 and 3 and Table 1).

The column dimensions of all model buildings were 150x150 mm, and the beam dimensions were 100x150 mm in the transverse direction $(\mathrm{Z})$ and $80 \times 150 \mathrm{~mm}$ in the horizontal direction $(\mathrm{X})$. The typical column of the frame buildings was reinforced with eight bars with a diameter of $25 \mathrm{~mm}$, while the beams were reinforced with four bars with a diameter of $25 \mathrm{~mm}$ (Fig. 4). Table 1 presents the mechanical properties of the model frame buildings, and Fig. 4 depicts the geometrical properties of the model beams and columns in two stages.

Two stages comprise four structural models analysed using Arcs 3D software. The first stage represented the analysis of two models of three-storey and six-storey buildings (see Figs. 2(c) and 2(d)). The first stage consists of the separate analyses of the two models of three-storey and six-storey RC buildings using Arcs 3D software (see Figs. 3(c) and $3(\mathrm{~d}))$. 


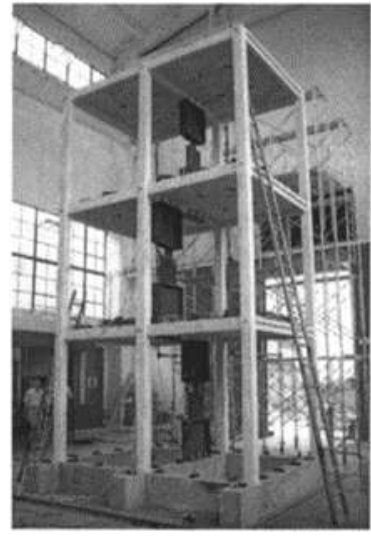

(a)

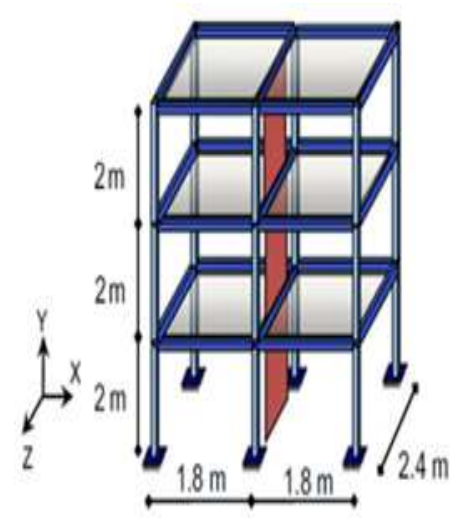

(b)

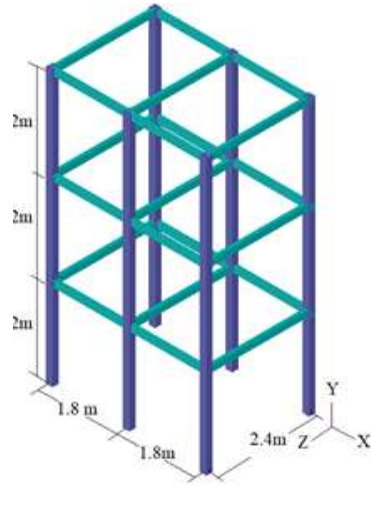

(c)

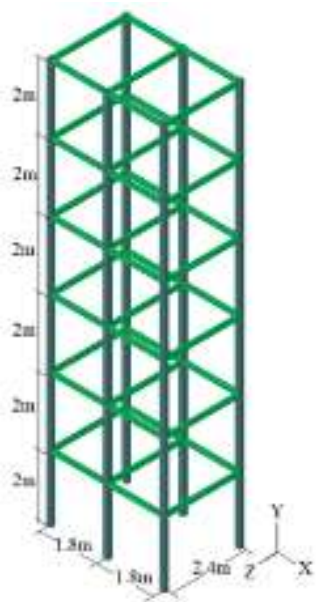

(d)

Fig. 2: Configuration and three-dimensional view frame model of (a) experimental study by Lu et al. (2008) [10], (b) numerical study by Farzad et al. (2015) [11], (c) three-storey building, and (d) six-storey building.

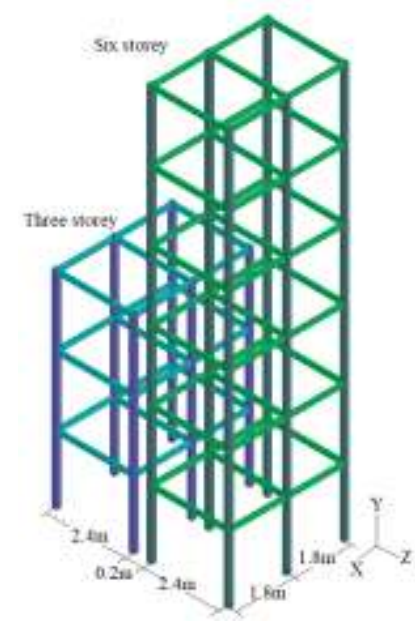

(a)

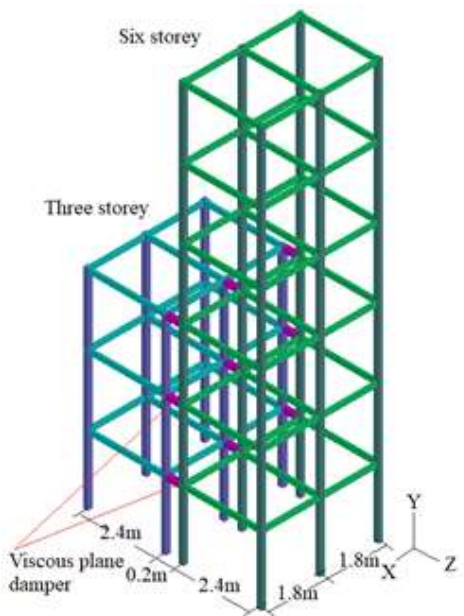

(b)

Fig. 3: Three-dimensional view of combining two buildings (a) without damper and (b) with viscous plane damper.

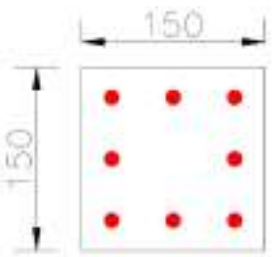

(a)

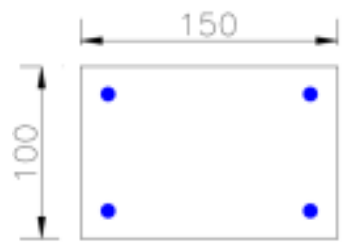

(b)

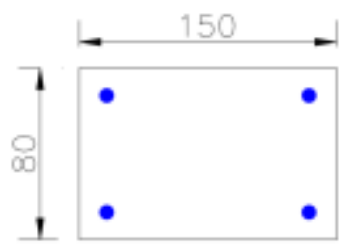

(c)

Fig. 4: Structural cross-section details of the frame buildings in mm for (a) columns, (b) transverse beams (Z), and (c) horizontal beams $(\mathrm{X})$. 
The second stage includes the analysis of two model RC buildings with different heights. Two models of combined three- and six-storey RC buildings were analysed with and without a viscous plane damper. The clear gap between the combined buildings was $50 \mathrm{~mm}$ in both models (see Figs. 3(a) and 3(b)).

Table 1: Mechanical properties of concrete and steel bars in the frame buildings[10, 11].

\begin{tabular}{|c|c|c|}
\hline Material & Properties & Values \\
\hline \multirow{2}{*}{ Concrete } & Cube compressive stress $\left(\mathrm{F}_{\mathrm{cu}}\right), \mathrm{MPa}$ & 20.00 \\
\cline { 2 - 3 } & Modulus of elasticity $\left(\mathrm{E}_{\mathrm{c}}\right), \mathrm{GPa}$ & 25.00 \\
\hline \multirow{3}{*}{ Steel bar } & Yield strength $\left(\mathrm{F}_{\mathrm{y}}\right), \mathrm{MPa}$ & 360.00 \\
\cline { 2 - 3 } & Ultimate strength $\left(\mathrm{F}_{\mathrm{u}}\right)$ & 530.00 \\
\cline { 2 - 3 } & Modulus of elasticity $(\mathrm{Es}), \mathrm{GPa}$ & 196.00 \\
\hline
\end{tabular}

\section{Modelling Structural Buildings}

The Arcs 3D software can build and analyse two buildings to present the maximum displacement in the horizontal $(\mathrm{X})$, transverse $(\mathrm{Z})$, and vertical $(\mathrm{Y})$ directions. The nonlinear dynamic analysis was applied in the two stages of the four models. The seismic behaviour was analysed using time history for the models of the buildings. The maximum displacement of the first stage was evaluated for each model for each storey in the horizontal (X), transverse (Z), and vertical directions (Y) (see Fig.5 (a) and (b)). In contrast, in the second stage of the analysis, the maximum displacements of the combined two buildings with and without viscous plane damper were evaluated (see Fig. 5(c) and 5(d)).

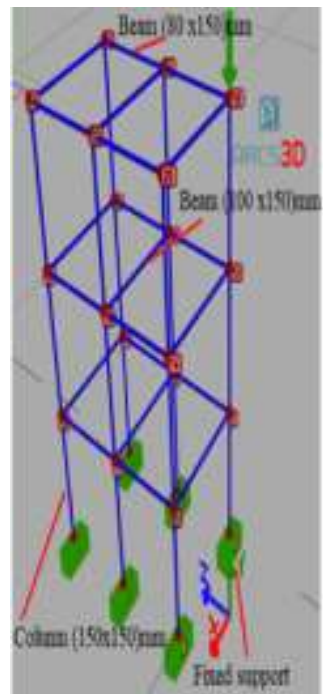

(a)

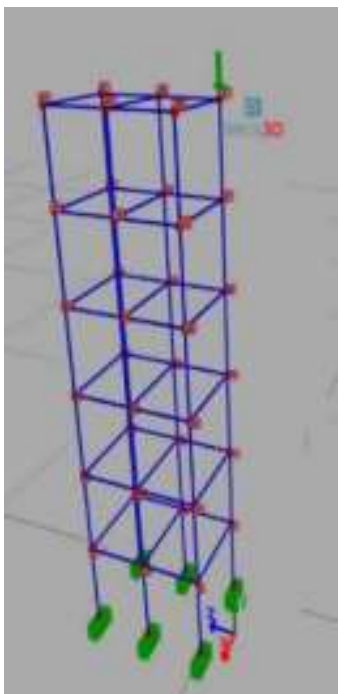

(b)

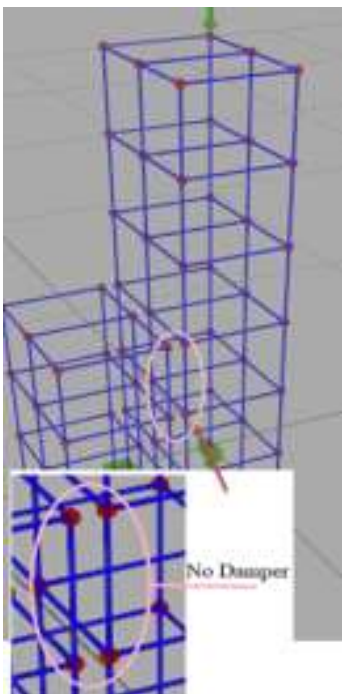

(c)

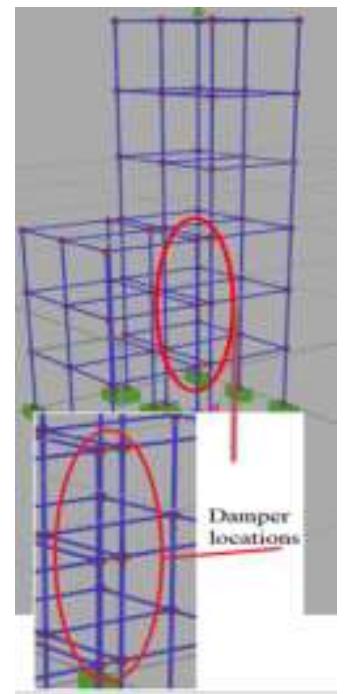

(d)

Fig. 5: Building model of the (a) three-storey, (b) six-storey, (c) and combined buildings without damper and (d) the combined buildings using the viscous plane damper.

The damper used in this study is an innovative viscous plane damper, applied between the gaps of two buildings at the joint for each storey in the transverse direction (Z) (see Fig. 6). The analysis results of the three-storey building were validated with experimental [10] and numerical [11] results to verify the results of the other models. 


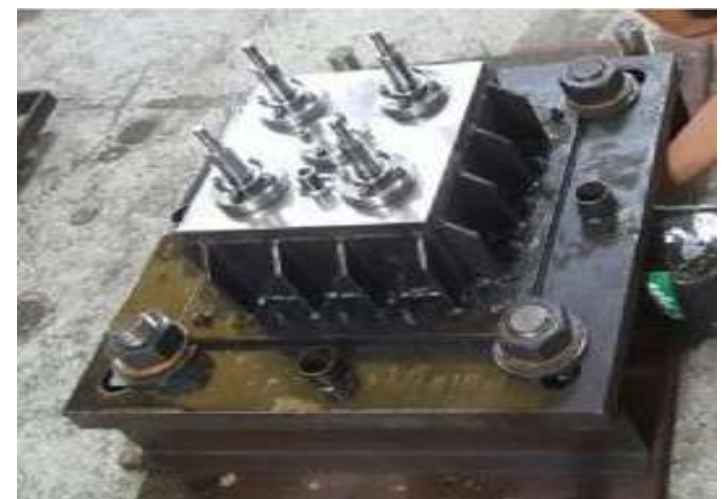

Fig. 6: New technique of the viscous plane damper.

\section{Results and Discussion}

\subsection{Validation Displacement Results of Three-storey and Six-storey Buildings}

The validation results of the three-storey buildings in the experimental, numerical, and modelling analyses presents in Fig.7.

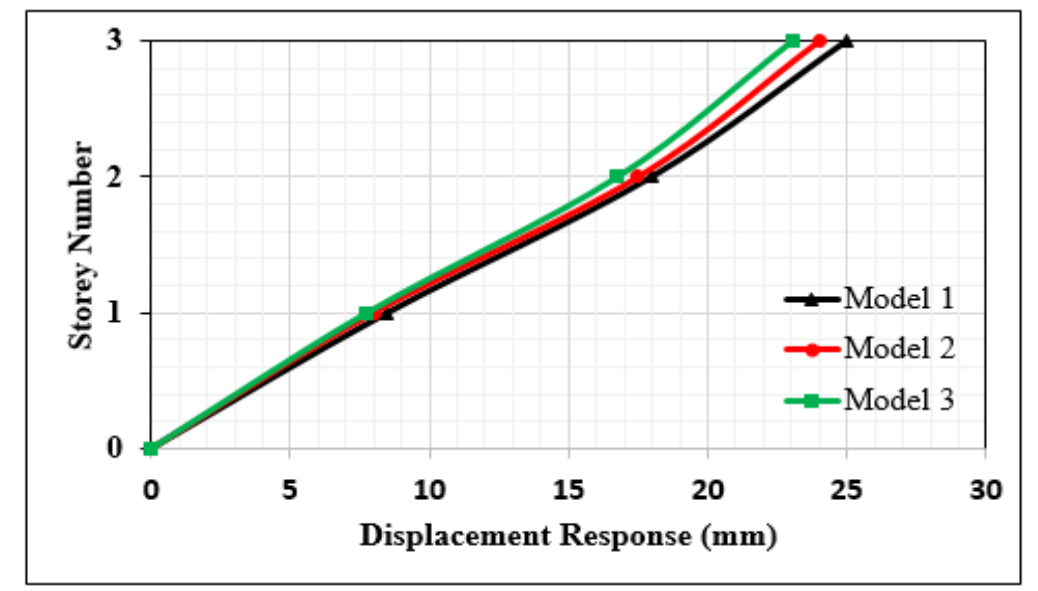

Fig. 7: Validation of the results in terms of maximum displacement by storey number of buildings (up to three).

The maximum displacements of the three-storey building in the horizontal (X) direction, the vertical (Y) direction, and the transverse $(Z)$ direction were $23.02 \mathrm{~mm}, 0.08 \mathrm{~mm}$ and $8.80 \mathrm{~mm}$, respectively (Fig. 8). 


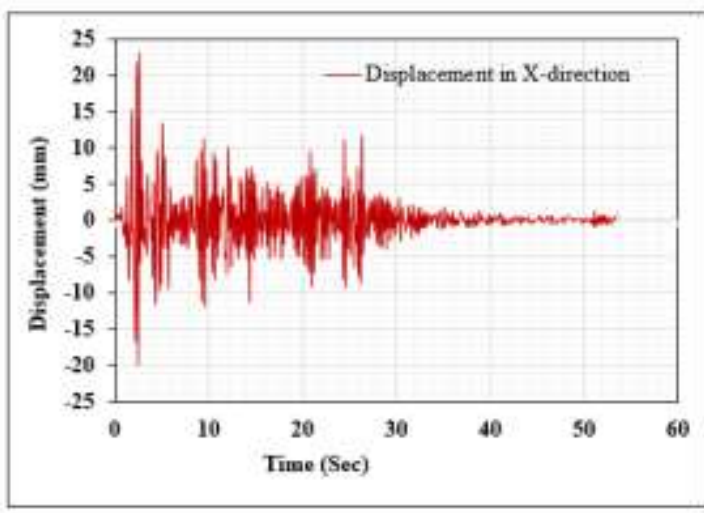

(a)

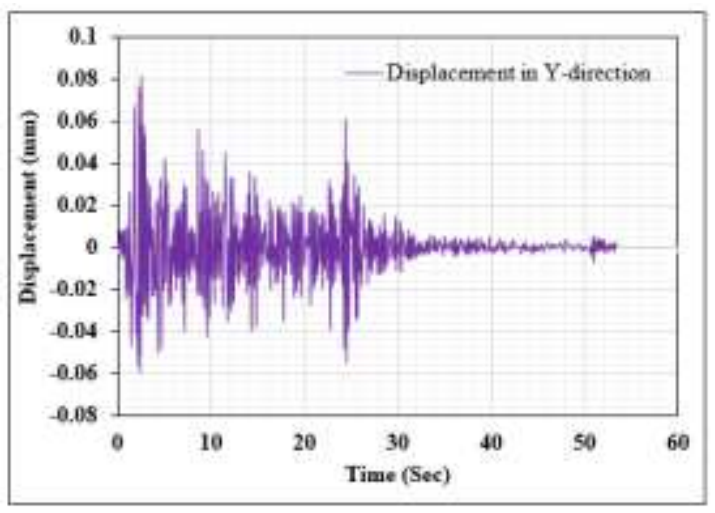

(b)

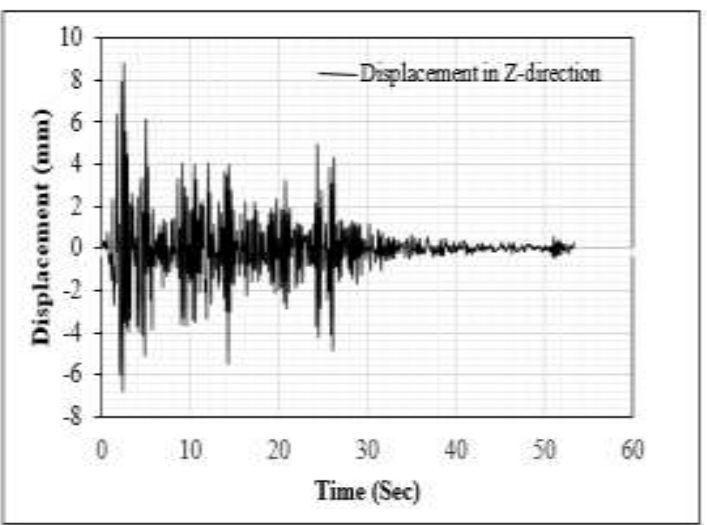

(c)

Fig. 8: Maximum displacement results of three-storey building in (a) horizontal (X), (b) vertical (Y), and (c) transverse (Z) directions.

In Table 2, Model 1 (M1) represents the experimental results [10]. Model 2 (M2) represents the numerical results [11], and Model 3 (M3) denoted the results of this study. The accuracy ratio was above $91 \%$. The results achieved good agreement with the experimental and numerical results. Thus, the maximum displacement results for the six-storey building were $54.40 \mathrm{~mm}, 0.45 \mathrm{~mm}$, and $29.70 \mathrm{~mm}$, in the X, Y, and Z directions, respectively (see Fig.9).

Table 2: Maximum displacement results of three models of buildings up to three storeys.

\begin{tabular}{|c|c|c|c|c|c|}
\hline $\begin{array}{c}\text { Number of } \\
\text { Storeys }\end{array}$ & $\begin{array}{c}\text { Displacement of } \\
\text { Model 1 (M1) [10], } \\
(\mathrm{mm})\end{array}$ & $\begin{array}{c}\text { Displacement of } \\
\text { Model 2 (M2) } \\
{[11],(\mathrm{mm})}\end{array}$ & $\begin{array}{c}\text { Displacement of Model 3 } \\
(\mathrm{M} 3),(\mathrm{mm})\end{array}$ & \multicolumn{2}{|c|}{$\begin{array}{c}\text { Accuracy Ratio } \\
(\%)\end{array}$} \\
\hline 0 & 0 & 0 & 0 & M3/M1 & M3/M2 \\
\hline 1 & 8.5 & 8 & 7.76 & 91.29 & 97.00 \\
\hline 2 & 18.0 & 17.5 & 16.75 & 93.06 & 95.71 \\
\hline 3 & 25.0 & 24.0 & 23.02 & 92.08 & 95.92 \\
\hline
\end{tabular}




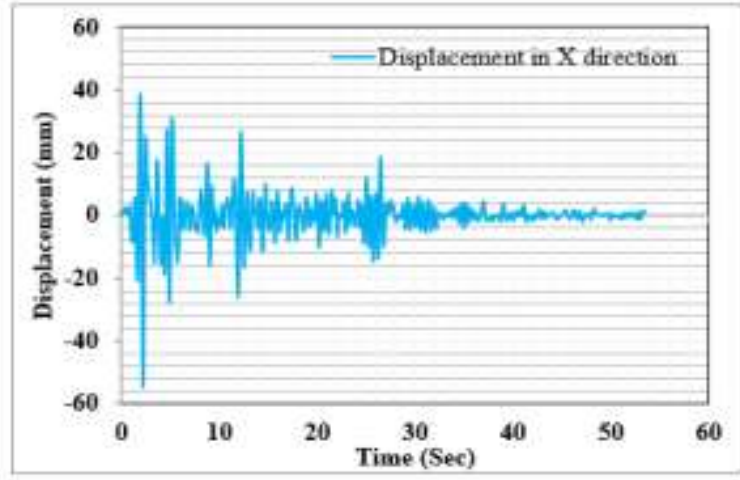

(a)

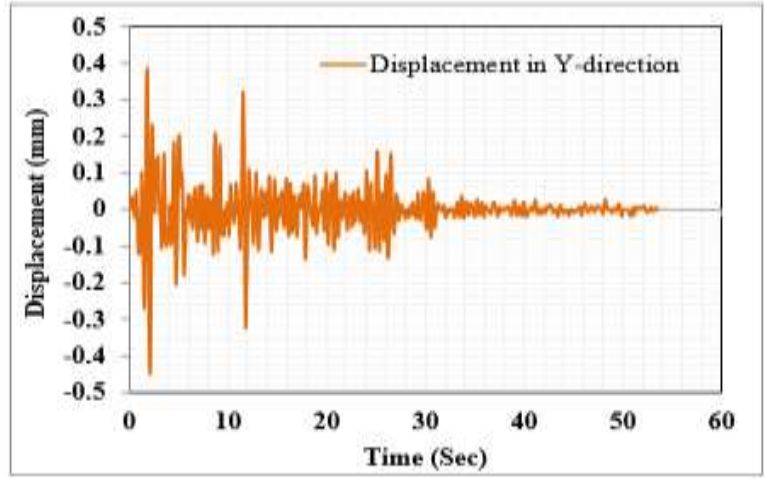

(b)

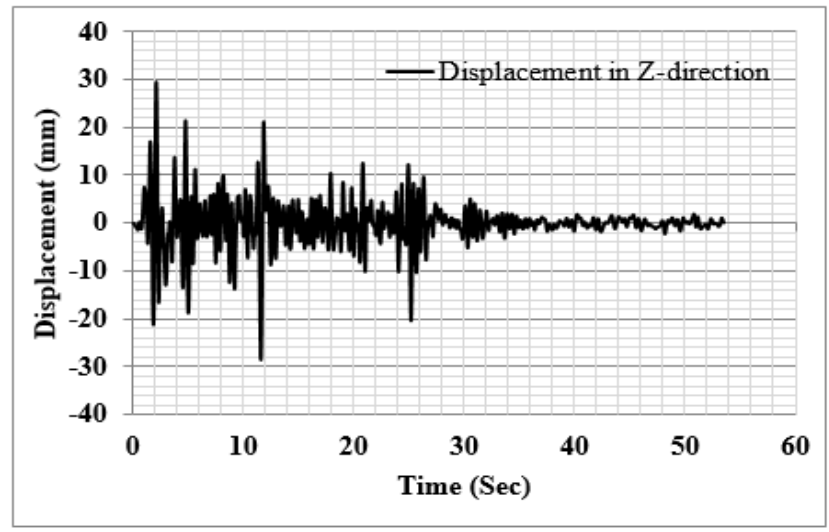

(c)

Fig. 9: Maximum displacement results of six-storey building in the (a) horizontal (X), (b) vertical (Y), and (c) transverse (Z) directions.

\subsection{Displacement Results of Combined Buildings with and without Damper}

The maximum displacement results of the combined three-storey and six-storey buildings without damper were 33.40 $\mathrm{mm}$ in the horizontal $(\mathrm{X})$ direction, $0.43 \mathrm{~mm}$ in the vertical $(\mathrm{Y})$ direction, and $49.10 \mathrm{~mm}$ in the transverse $(\mathrm{Z})$ direction (see Fig. 10). In addition, the maximum displacement results of the $\mathrm{X}, \mathrm{Y}$, and $\mathrm{Z}$ directions of the combined two buildings with damper were $24.90 \mathrm{~mm}, 0.37 \mathrm{~mm}$, and $31.67 \mathrm{~mm}$, respectively (see Fig. 10). The use of the damper decreased the displacement in all directions. The displacements decreased by $23.1 \%$ in the horizontal (X) direction, $14 \%$ in the vertical (Y) direction, and $35.5 \%$ in the transverse $(\mathrm{Z})$ direction, as presented in Table 3. Fig.11 presents the pounding effect of the adjacent models of combined RC buildings.

Table 3: Maximum displacement results of combining the two buildings with and without a damper.

\begin{tabular}{|c|c|c|c|}
\hline Direction & $\begin{array}{l}\text { Maximum displacement } \\
\text { (without damper), mm }\end{array}$ & $\begin{array}{l}\text { Maximum displacement } \\
\text { (with damper), mm }\end{array}$ & Decreasing Ratio (\%) \\
\hline X-direction & 32.40 & 24.90 & 23.10 \\
\hline Y-direction & 0.43 & 0.37 & 14.00 \\
\hline Z-direction & 49.10 & 31.67 & 35.50 \\
\hline
\end{tabular}




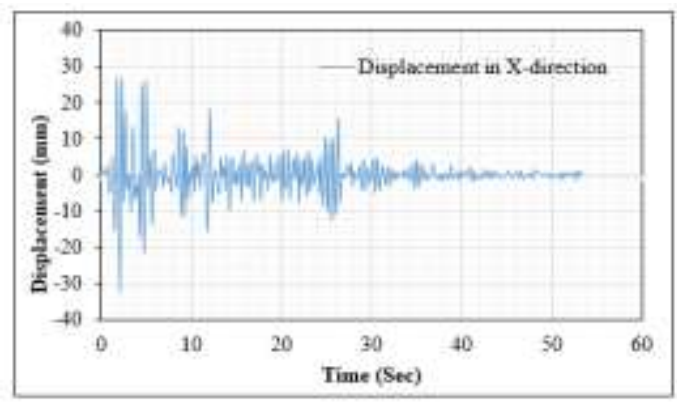

(a)

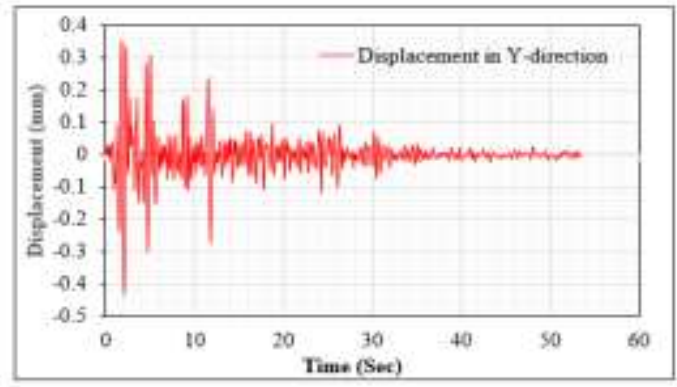

(c)

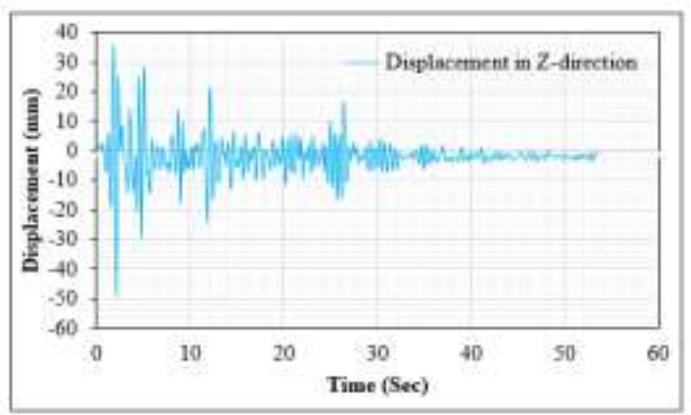

(e)

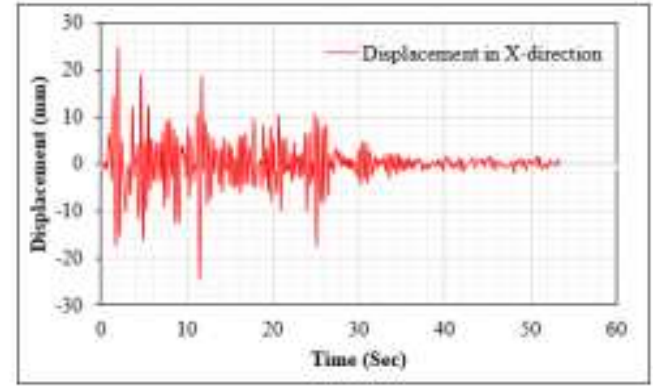

(b)

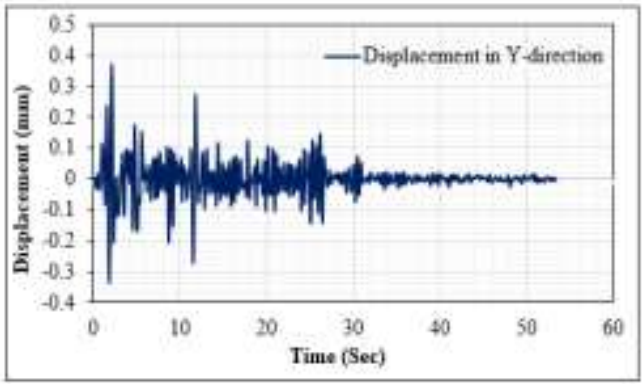

(d)

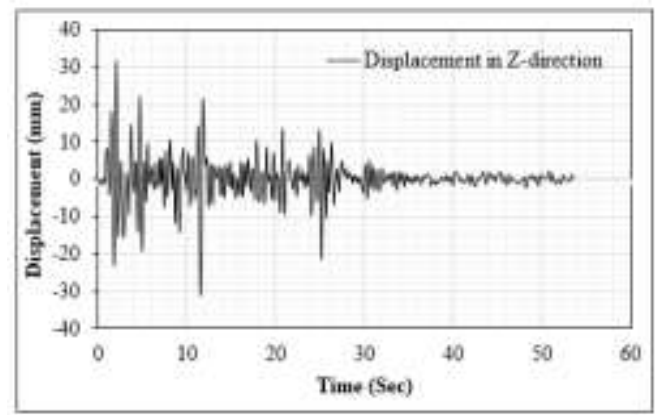

(f)

Fig. 10: Maximum displacement of the two combined RC buildings in the (a) $\mathrm{X}$-direction without damper, (b) $\mathrm{X}$ direction with damper, (c) Y-direction without damper, (d) Y-direction with damper, (e) Z-direction without damper, and (f) Z-direction with damper. 


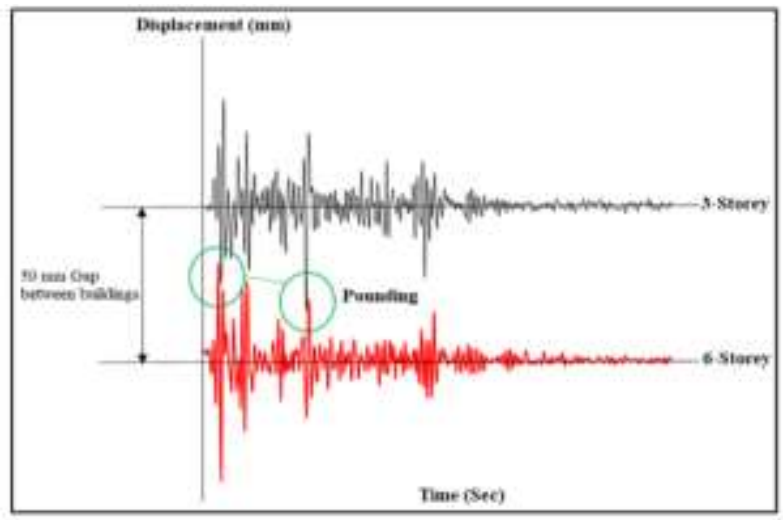

(a)

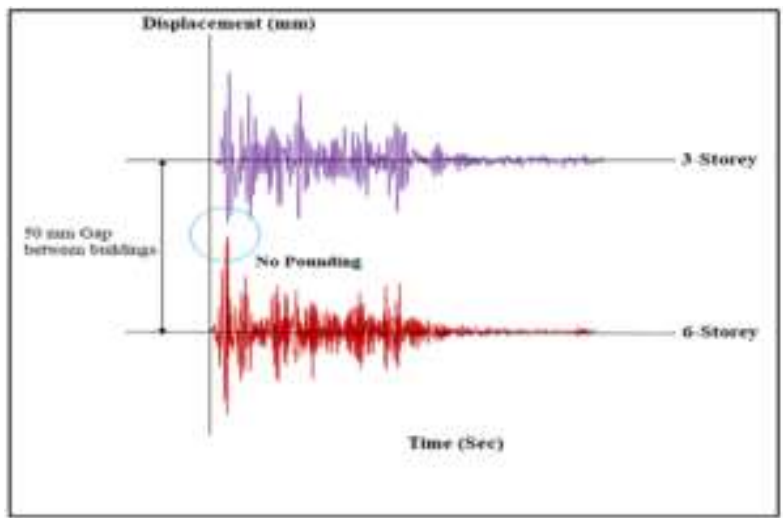

(b)

Fig. 11: Pounding effect of the analysis results of adjacent RC buildings at different heights (a) without damper and (b) with viscous plane damper.

\section{Conclusions}

In this study, an innovative viscous plane damper was used to analyse RC structural buildings using Arcs 3D software to evaluate the pounding of adjacent buildings. The results achieved a good agreement and accurate results compared with experimental and numerical results. According to the validation results of three- and six-storey buildings, two models of adjacent RC buildings with different heights were created to analyse the pounding effect of buildings with and without a damper. The results show that the viscous plane damper can reduce the pounding between adjacent buildings. Thus, the model analysis results of the combined adjacent RC buildings with different heights can evaluate seismic behaviour with accuracy. Therefore, based on the results of this study, the following conclusion are drawn:

1. The model of a three-storey building achieved accurate results in terms of maximum displacement compared with the experimental and numerical results. The average accuracy of the displacement of the model analysis in this study reached $92.14 \%$ and $96.21 \%$, compared with M1 and M2, respectively.

2. The model analysis of a six-storey building attained accurate results compared with the model of the three-storey building. Thus, it may indicate that this model was built well.

3. Applying the viscous plane damper between two RC adjacent buildings with different heights reduced the displacements in the horizontal $(\mathrm{X})$, vertical $(\mathrm{Y})$, and transverse $(\mathrm{Z})$ directions by $23.10 \%, 14.00 \%$, and $35.50 \%$, respectively. Thus, the pounding effect between RC buildings with different heights was not appeared.

4. Utilising a new viscous plane damper between the adjacent $\mathrm{RC}$ buildings can significantly reduce the pounding effect in a seismic zone due to the reduction in displacements of the adjacent RC buildings in all directions.

\section{Acknowledgements}

This work received financial support from the University Putra Malaysia under Putra grant No. 9531200. This support is gratefully acknowledged.

\section{References}

[1] C. Rajaram and P. K. Ramancharla, "Three dimensional analysis of pounding between adjacent buildings," Journal of Structural Engineering, vol. 41, no. 2, pp. 1-11, 2014.

[2] G. R. Miyamoto, "Niigata Chuetsu-Oki Japan Earthquake Reconnaissance Report," Miyamoto, GR (ed.), 2007. 
[3] B. Kafle, A. Mohyeddin-Kermani, and A. Wibowo, "A report on the visit to the region stricken by the Wenchuan Earthquake," Appendix to the Special Issue on Earthquake Engineering in the Low and Moderate Seismic Region of Southeast Asia and Australia, Electronic Journal of Structural Engineering, 2008.

[4] M. Çelebi, P. Bazzurro, L. Chiaraluce, P. Clemente, L. Decanini, A. DeSortis, W. Ellsworth, A. Gorini, E. Kalkan, S. Marcucci, G. Milana, F. Maollaioli, M. Olivieri, R. Paolucci, D. Rinaldis, A. Rovelli, F. Sabetta, C. Stephens, "Recorded motions of the 6 April 2009 Mw 6.3 L'Aquila, Italy, earthquake and implications for building structural damage: overview," Earthquake Spectra, vol. 26, no. 3, pp. 651-684, 2010.

[5] S. A. Anagnostopoulos, "Pounding of buildings in series during earthquakes," Earthquake engineering \& structural dynamics, vol. 16, no. 3, pp. 443-456, 1988.

[6] M. Papadrakakis, C. Apostolopoulou, A. Zacharopoulos, and S. Bitzarakis, "Three-dimensional simulation of structural pounding during earthquakes," Journal of Engineering Mechanics, vol. 122, no. 5, pp. 423-431, 1996.

[7] E. Leibovich, A. Rutenberg, and D. Yankelevsky, "On eccentric seismic pounding of symmetric buildings," Earthquake engineering \& structural dynamics, vol. 25, no. 3, pp. 219-233, 1996.

[8] K. Chau and X. Wei, "Pounding of structures modelled as non-linear impacts of two oscillators," Earthquake engineering \& structural dynamics, vol. 30, no. 5, pp. 633-651, 2001.

[9] L. Gong and H. Hao, "Analysis of coupled lateral-torsional-pounding responses of one-storey asymmetric adjacent structures subjected to bi-directional ground motions Part I: Uniform ground motion input," Advances in Structural Engineering, vol. 8, no. 5, pp. 463-479, 2005.

[10] X. Lu, Y. Zhou, and F. Yan, "Shaking table test and numerical analysis of RC frames with viscous wall dampers," Journal of Structural Engineering, vol. 134, no. 1, pp. 64-76, 2008.

[11] F. Hejazi, M. D. Shoaei, A. Tousi, and M. Jaafar, "Analytical model for viscous wall dampers," Computer-Aided Civil and Infrastructure Engineering, vol. 31, no. 5, pp. 381-399, 2016. 